\title{
Incorporation of humic-derived active molecules into compound NPK granulated fertilizers: main technical difficulties and potential solutions
}

\author{
J. Erro ${ }^{1}$, O. Urrutia ${ }^{1}$, R. Baigorri' ${ }^{2}$ M. Fuentes ${ }^{1}$, A. M. Zamarreño ${ }^{1}$ and J. M. Garcia-Mina ${ }^{1 *}$
}

\begin{abstract}
Numerous studies carried out both in open field and laboratory scale have provided experimental evidence for a beneficial action of humic substances (HS) on plant growth and mineral nutrition. In fact, many products containing diverse concentrations of humic substances, mainly humic and fulvic acids, are marketed as plant growth enhancers all over the world. However, the incorporation of molecules containing humic substances into the granules of compound NPK fertilizers is not a common practice mainly due to technical difficulties and problems associated with the manufacture process of these mineral fertilizers. These problems are normally linked to the potential deleterious effects of granulation conditions (principally, heat and $\mathrm{pH}$ ) on the structure and properties of molecules containing humic substances. In this review, we discuss several strategies for the incorporation of active molecules containing humic substances into granules of NPK compound fertilizers as well as the main constraints that have to be considered in this process, which normally depend on the agronomical results intended with the preparation of special humic-containing NPK compound fertilizers. We also discuss why, in our opinion, the beneficial action of HS in NPK compound fertilizers is more related to the "so called" indirect effects of HS on plant growth than to the "so called" direct effects.
\end{abstract}

Keywords: Humic substances, Humic acid, Fulvic acid, Metal-humic complexes, Anion (phosphate)-metal-humic complexes, NPK granule, NPK compound fertilizers, Fertilizer technology, Fertilizer granulation, Plant mineral nutrition

\section{Background}

It has been well established that soil fertility, and therefore crop yields and fruit quality, is principally related to three main complementary components of soil ecosystems: natural organic matter (NOM), soil microbiota and the pool of bioavailable mineral nutrients $[1,2]$.

As for the relevant role of NOM in plant development, many studies indicated that it is associated with the activity of specific organic fractions present in soil solutions (dissolved organic matter; DOM) and soil matrix (soil organic matter; SOM), which have been operatively

\footnotetext{
*Correspondence: jgmina@unav.es

${ }^{1}$ Department of Environmental Biology, Agricultural Chemistry and Biology Group/CMI Roullier, Faculties of Sciences and Pharmacy, University of Navarra, c/Irunlarrea 1, 31080 Pamplona, Navarra, Spain Full list of author information is available at the end of the article
}

defined as humic substances (HS) and their fractions humic acids (HA), fulvic acids (FA) and Humin $[1,3]$.

The beneficial action of HS in crop production has been ascribed to two main complementary HS actions on plant-soil systems $[4,5]$ :

(i) HS effects expressed as a consequence of their previous action on soil properties and fertility. These effects are known as indirect effects (IE) and mainly result from the ability of HS to form stable natural chelates or complexes with metals in soil [3]. This action influences soil texture and the pool of mineral nutrients available for plants and microbiota [4].

(ii) HS effects expressed as a consequence of events resulting from the direct interaction of HS with cell membranes at root or leaf surfaces. These effects are 
known as direct effects (DE) and affect shoot and root growth through a complex network of signaling pathways regulated by the main plant hormones and effectors, such as auxin, nitric oxide, ethylene, abscisic acid, cytokinins and reactive oxygen species [5].

Besides that, there exist some factors that also influence the intensity of HS-IE and HS-DE on plant development, which might be classified as intrinsic (those factors related to HS intrinsic physicochemical properties: structure-conformation, size distribution, etc.) and extrinsic (those factors related to crop management, the presence of abiotic or biotic stresses, soil properties, species of plant, moment of application and doses, mode of application-foliar or soil-etc.) $[4,6]$. All these facts are summarized in Fig. 1.

It is because of these positive actions of HS on plant growth and, thereby, crop yields, that HS are extensively used in agricultural practices $[1,2,4,6,7]$.

In general, apart from pelletized or powder organic amendments based on composts, biochar, leonardite, etc., most HS products available in the market consist of formulations containing HS (or micronutrient-humic complexes) as the main ingredient, either in liquid or solid (water soluble) formulation [8]. These products are normally costly and are used in specialized horticultural crops by root application (drip irrigation for instance) or sprayed on the leaf (foliar sprays) [7, 8]. However, the development of products based on the action of HS improving nutrient bioavailability in soil (IE) and incorporated to granulated compound NPK fertilizers is scarce $[9,10]$. This fact is likely due to the limited knowledge about the potential effects of the technology involved in compound NPK fertilizer manufacture on the stability and structure, and therefore agronomical efficiency, of compound fertilizers containing HS.

In this framework, the main aims of this work are:

(i) To summarize briefly experimental evidence supporting the relevant role of humic substances in providing available mineral nutrients to plants growing in soils favoring nutrient deficiencies.

(ii) To describe and discuss the limitations (technical difficulties) and opportunities of chemical processes involved in the manufacture of granulated compound fertilizers in relation to the application of humic-based compounds in these types of fertilizers.

Another important remark is that we do not consider in our study products based on the incorporation of HS into compound NPK granules with the aim of also having biostimulant (DE) effects. This is because the amount of active HS that would be necessary to introduce in the formula to achieve consistent agronomical results is too

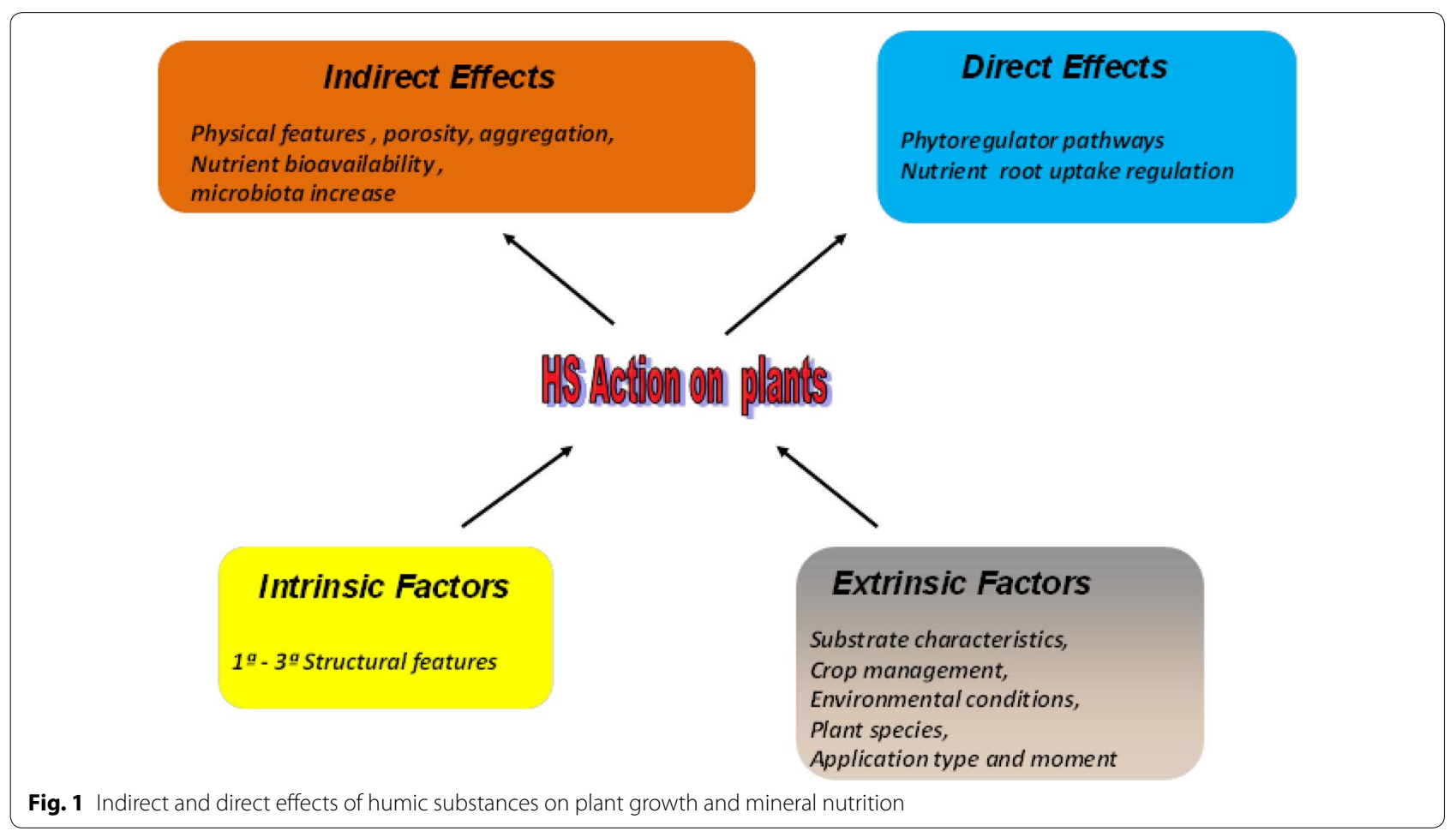


much high (around $75 \mathrm{~kg}$ per ha) [4] to be affordable from both economic and technical viewpoints, as will be discussed later on.

So, we consider in this review the incorporation into compound NPK fertilizer granules of molecules containing HS with the ability to improve the root uptake of some mineral nutrients.

\section{Main HS-IE on plant growth and mineral nutrition}

The IE of HS on plant growth and mineral nutrition are directly associated with their chemical reactivity mainly related to their ability to form stable complexes with metals, and have high relevance in the whole action of HS on plant development $[3,11,12]$. This fact becomes very clear in those natural and agricultural ecosystems where the concentration of HS in soil solution, and therefore in the rhizosphere, is too much low to show a direct action on plant growth [13]. This is the case of the soil application of HS in industrial, arable crops or fruit trees orchards growing in open field without drip irrigation or sprinkle irrigation.

Among these types of HS effects, the most important are specific actions on the plant growth medium (soils, substrates), either with physical character like soil porosity, soil aggregation, water permeation, gas exchanger, with chemical character mainly associated with nutrient bioavailability, or in some cases with biological character as well by affecting soil microbiota activity [4, 14].

In general, all these actions of HS on soil or substrates result from a singular ability of HS to form stable complexes with multivalent metals like $\mathrm{Ca}^{++}, \mathrm{Mg}^{++}, \mathrm{Cu}^{++}$, $\mathrm{Zn}^{++}, \mathrm{Fe}^{+++}$or $\mathrm{Mn}^{n+}$ among others $[11,12]$. This chemical feature of HS improves physical soil properties favoring the formation of stable clay-humic aggregates through cation bridges, and soil fertility increasing mineral nutrient (P, Fe, Mn or Zn) availability for plants grown in alkaline and calcareous soils [15]. In fact, several studies have reported that a very significant fraction of $\mathrm{Cu}, \mathrm{Zn}, \mathrm{Fe}$ and $\mathrm{Mn}$ in soil solution from limy, alkaline soils was present in the form of complexes with DOM [16-18].

\section{Cation complexing ability of HS}

The ability of HS to form stable natural chelates (or complexes) with multivalent cations has been studied for many years and its relevance in the transport and dynamics of metals in natural ecosystems has been well established [12].

Although HS are very complex, heterogeneous and polydisperse molecular systems, the complementary use of instrumental techniques like ${ }^{13} \mathrm{C}-\mathrm{NMR}$ and FTIR allowed the clear identification of oxygen-containing groups (like carboxylic, phenolic, or hydroxyl) and
$\mathrm{N}$-containing groups like amines distributed throughout the whole primary structure of HS in both aromatic and aliphatic domains [3] (Fig. 2) and able to bind metals [11, 12]. Thus, experimental evidence indicated the presence in the main structure of HS of metal-binding sites such as salicylic-, phthalic- or catechol-type [3,11] (Fig. 3).

Further, the use of these techniques along with others like elemental analysis or size distribution analysis allowed the identification of functional-supramolecular-aggregates in HS in which these binding sites are distributed [19]. Likewise, the use of mathematical models, either empirical (semi-empirical) or explicative, allowed the determination of apparent and intrinsic stability constants for these metal complexes and the effects of environmental variables (temperature, $\mathrm{pH}$ or ionic strength) on these parameters as well $[12,20]$.

On the other hand, some studies have shown that humic complexes containing micronutrients $(\mathrm{Fe}, \mathrm{Zn}, \mathrm{Cu}$ or $\mathrm{Mn}$ ) can be used to improve the uptake of complexed micronutrients by plants roots, although their efficiency seems to be subjected to some constraints $[4,14,21]$. As will be discussed below, these constraints were mainly related to metal-humic complexes structure and properties, mainly stability and solubility-mobility in soil solutions $[21,22]$.

As for $\mathrm{Cu}$ and $\mathrm{Zn}$ plant nutrition, it has been well established that both $\mathrm{Zn}$ and $\mathrm{Cu}$ deficiencies can be developed in plants cultivated in both alkaline-calcareous soils (precipitation of $\mathrm{Cu}$ hydroxides and $\mathrm{Cu}, \mathrm{Zn}$ carbonates; clay fixation) and acidic soils (fixation in poorly humified organic matter, clays and Fe oxides) [23]. Some studies have shown the ability of $\mathrm{Cu}$-humic complexes to affect $\mathrm{Cu}$ uptake by plants cultivated in silica sand [24-27].

These effects varied according to the stability of $\mathrm{Cu}$ binding in HS [24, 25]. Further studies showed that the application of stable and soluble $\mathrm{Cu}-\mathrm{HA}$ complexes was able to increase the root uptake and further translocation of $\mathrm{Cu}$ in alfalfa and wheat plants grown in both acidic and calcareous soils [21]. In the case of $\mathrm{Zn}$, several studies have reported the ability of $\mathrm{Zn}$-humic complexes to provide available $\mathrm{Zn}$ for plants growing in both inert substrate [28] and hydroponics [29]. However, the results in plants grown in soil are less conclusive. Kumar and Prasad [30] studied the effect Zn (labeled Zn)-fulvic complexes on maize grown in an alkaline, calcareous soil. They observed that plants were able to take up $\mathrm{Zn}$ from these complexes and showed better growth than plants treated with $\mathrm{Zn}$ sulfate. These results correlated well to diffusion coefficients in soil of $\mathrm{Zn}$-fulvic complexes [30]. However, the fraction $\mathrm{Zn}$ supplied by fulvic complexes was poorly taken up by plants (only around $7 \%$ ). The authors proposed that improvements in plant growth and $\mathrm{Zn}$ uptake might result from the biostimulant action of 


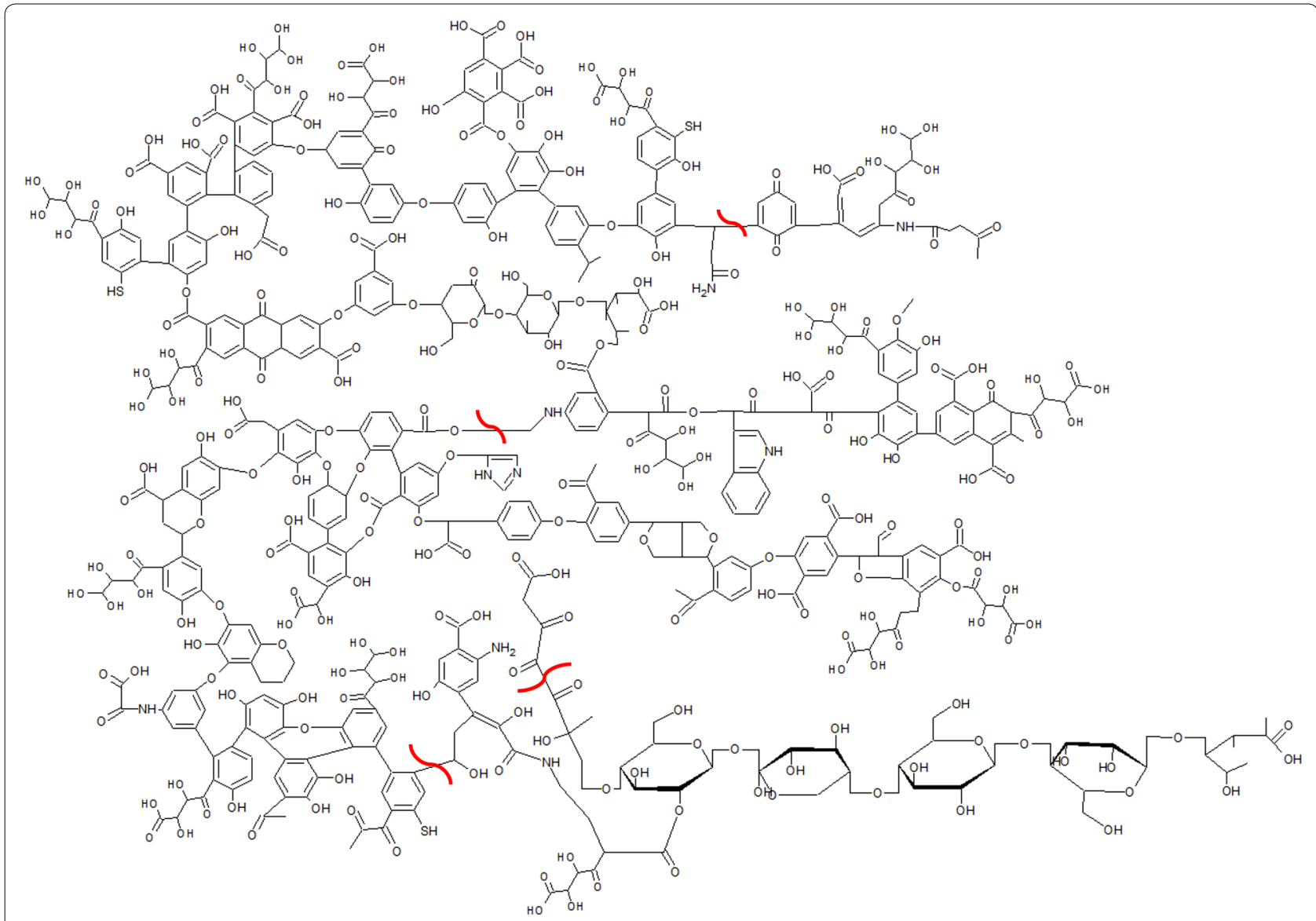

$\checkmark \quad$ Existence of weak attraction forces in a supramolecular conformation

Fig. 2 Hypothetical primary structure of a leonardite humic acid
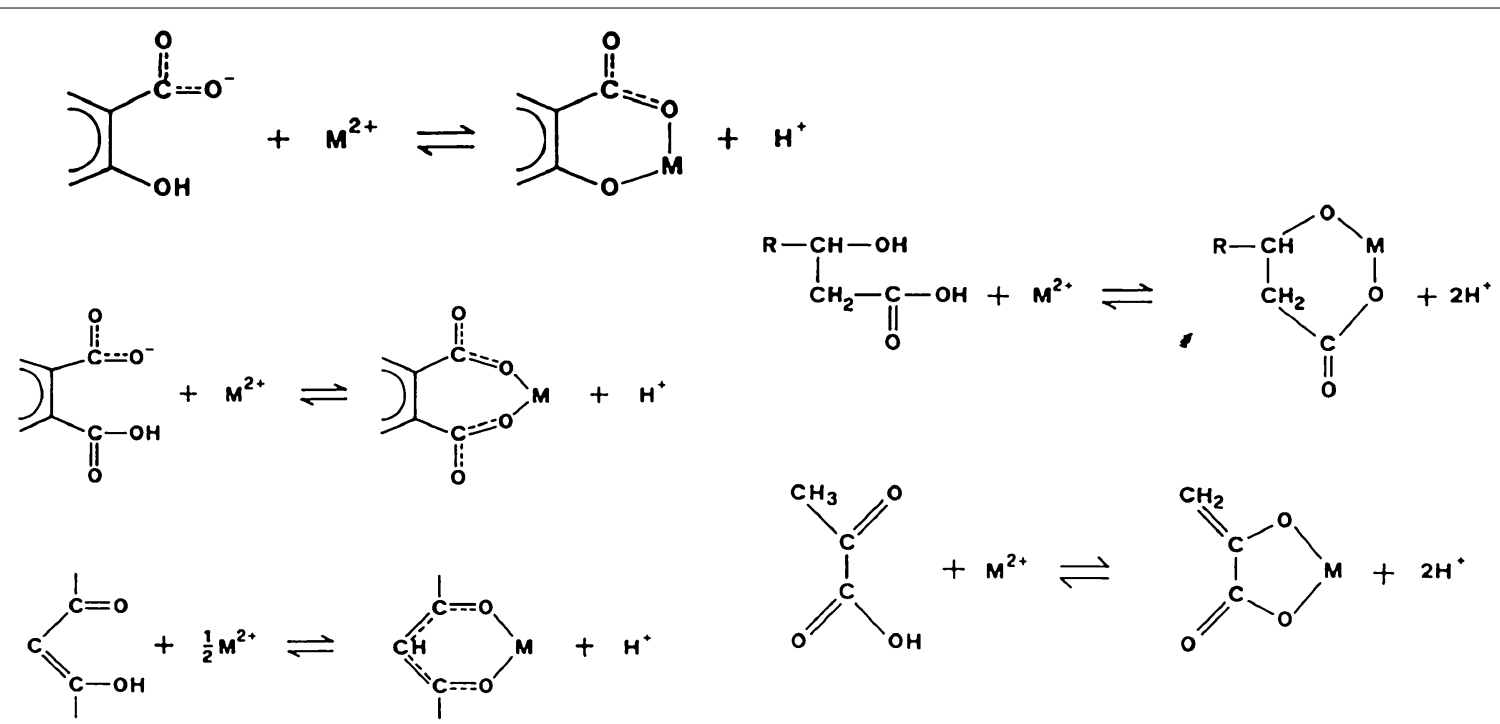<smiles>C#[14C][14C](=O)C(C)=O</smiles><smiles>O=C1ON=[P+]O1</smiles>

Fig. 3 Main functional groups and structural domains, able to complex metals 
fulvic acids. In fact, control plants did not show clear $\mathrm{Zn}$ deficiency [30]. Further studies reported that the application of $\mathrm{Zn}$-humic complexes with enough stability and solubility in soil solution increased $\mathrm{Zn}$ concentration in shoots of alfalfa and wheat plants grown in acidic and calcareous soils [21].

As to Fe nutrition, several studies have shown the ability of different types of $\mathrm{Fe}-\mathrm{HS}$ complexes to provide available Fe to several plant species cultivated in hydroponics [29-33]. However, studies comparing the efficiency Fehumic complexes with inorganic Fe salts to correct iron deficiency in soil cultivated plants did not show clear differences between both types of Fe treatments. Burau et al. [34] compared the performance of Fe-HS complexes as sources of Fe for beans growing in an alkalinecalcareous soil with that of $\mathrm{FeCl}_{3}$. The authors did not find any difference among treatments [34]. It is interesting to note that $\mathrm{Fe}$-humic complexes prepared by Burau et al. [34] were highly loaded with Fe and thereby with poor potential mobility and solubility in soil solution. In line with this, Alva and Obreza [35] studied the effect of a humic material enriched in Fe, on Fe root uptake, in several varieties of orange trees and grapes cultivated in alkaline-calcareous soils. In general, trees responses were rather poor and final leaf $\mathrm{Fe}$ values were close to those corresponding to Fe deficiency [36]. As in the case of $\mathrm{Fe}$-humic complexes used by Burau et al. [34], this $\mathrm{Fe}-$ humic material contained a high concentration of complexed $\mathrm{Fe}(18 \% \mathrm{Fe})$ and $\mathrm{Fe}$-humic complexes probably were sparingly soluble in water. The study of Pandeya et al. [37], carried out in rice plants grown in a calcareous soil, clearly underlined the high correlation between Fe plant uptake and Fe-Humic complexes soil diffusion rates. Furthermore, Garcia-Mina et al. [21] observed that the ability of Fe-humic complexes to increase Fe root uptake and $\mathrm{Fe}$ concentration in leaves in several plant species grown in soils prone to Fe deficiency was more likely linked to Fe-HS complex solubility in soil solution than to their stability. Further studies showed that the stability and solubility of metal-humic complexes in water solution are governed by the relationships between the complexed metal:HS ratio and $\mathrm{pH}$-ionic strength (I) values [22] (Fig. 4).

In summary, even though the ability of metal-humic complexes to provide the complexed metal to plant roots is supported by much experimental evidence, their efficiency in soil cultivated plants is subjected to many constraints, which principally related to their solubilitymobility in soil solution $[4,14,21]$. It is therefore logical that the beneficial effects of metal-humic complexes in micronutrient root uptake varied depending on soil solution properties ( $\mathrm{pH}, \mathrm{I}$, elemental composition, etc.). However, it is noteworthy to mention the functional complementarity between plant nutritional difficulties when growing in specific soil types and natural mechanisms evolved by the nature, since both stability and solubility of metal ( $\mathrm{Fe}, \mathrm{Zn}, \mathrm{Cu}$ )-humic complexes are higher for those $\mathrm{pH}$ ranges that favor metal precipitation and potential bio-unavailability [12, 22].

Regarding the chemical interaction between HS and macronutrients, some studies have described the formation of hydrogen bonds between protonated carboxylic or phenolic groups in $\mathrm{HS}$ and urea, mainly at acidic $\mathrm{pH}$ [38]. However, these complexes are not stable enough to maintain urea molecules bound to HS structural domains upon interaction with soils [38]. Regarding ammonium or potassium, the monovalent nature of these cations allowed the formation of ionic salts with oxygen-containing functional groups in $\mathrm{HS}$ at alkaline $\mathrm{pH}$ [3]. However, these links are quite weak and do not lead to a significant protection of $\mathrm{NH}_{4}^{+}$or $\mathrm{K}^{+}$against leaching or soil fixation [38].

As for P-bioavailability in soils, some studies proposed the ability of HS to complex phosphate through cation bridges in soil solution of mainly acidic soils [39]. In fact, several studies reported that humic-metal complexes involving many diverse cations were able to complex significant amounts of phosphate in aqueous solutions with $\mathrm{pH}$ values ranked between 4 and 8 [40-42]. These results also showed that the stability of humic-metalphosphate complexes did not significantly vary with $\mathrm{pH}$ [42]. Indeed, further studies indicated that the formation of humic-metal-phosphate complexes depended on the stability of the metal-humic binding site: the higher the stability of the metal-humic binding site, the lower the possibility of formation of humic-metal-phosphate complexes through that metal-humic binding site [43]. Likewise, the electronic features of the cation complexed by $\mathrm{HA}$ also play an important role in the stability of phosphate complexation in metal-humic binding sites, with transition metals showing the highest stability [43].

Summarizing, all these results taken together indicate that the metal complexing ability of HS can be a very useful tool to produce two types of special NPK compound fertilizers with beneficial effects on mineral plant nutrition:

(i) Metal-humic complexes to be potentially used in compound granulated NPK fertilizers to improve micronutrient plant nutrition.

(ii) Phosphate-metal-humic complexes to be potentially used in compound granulated NPK fertilizers to improve phosphate plant nutrition.

The most important question raised now is: How must these humic-based compounds be introduced (or 

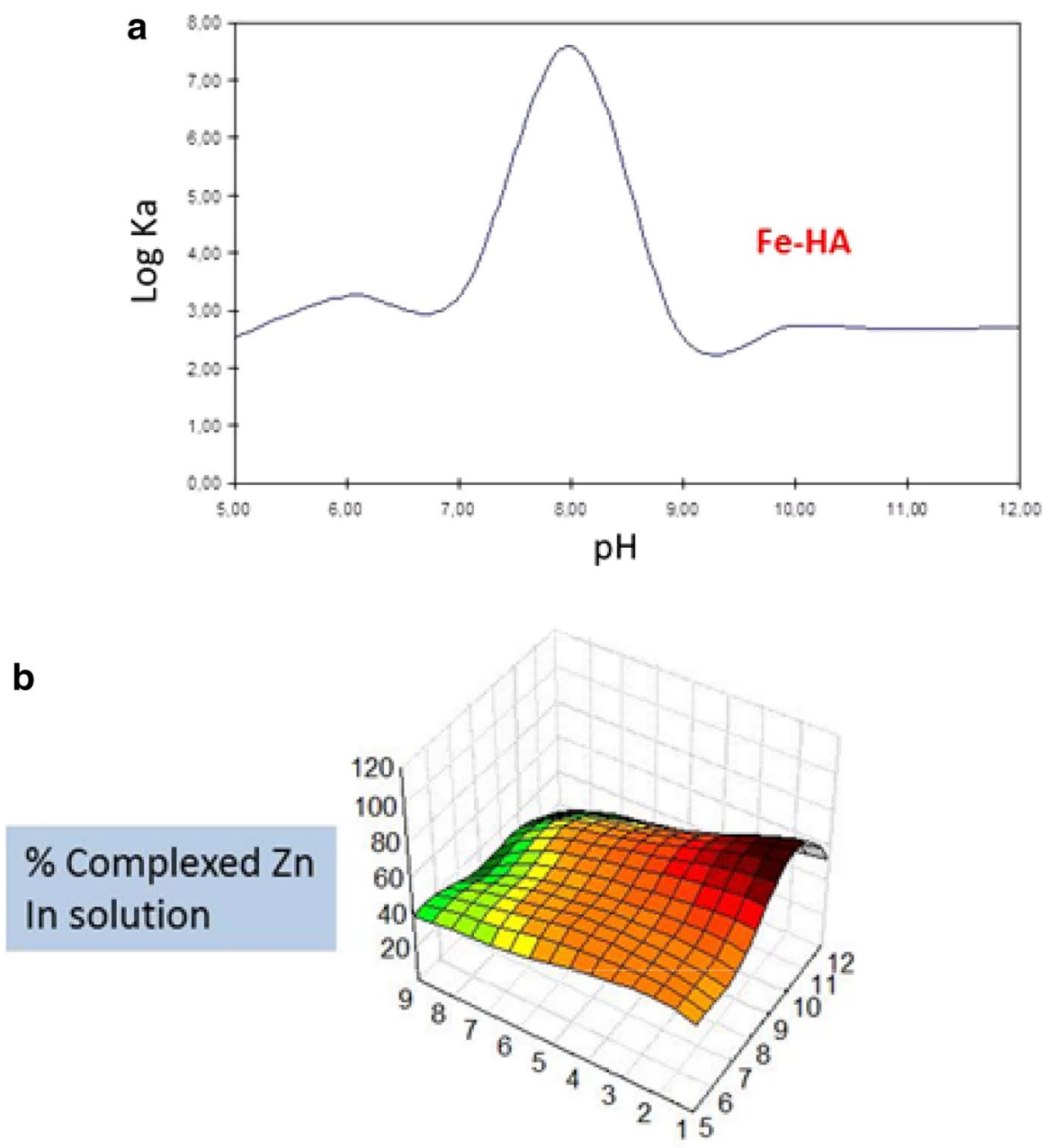

Fig. 4 Stability constant values of Fe-HA complex as a function of $\mathrm{pH}(\mathbf{a})$; solubility of $\mathrm{Zn}-\mathrm{HA}$ complex as a function of $\mathrm{pH}$ and $\mathrm{HA}: \mathrm{Zn}$ ratio in the complex (b). (unpublished results)

produced) into the main process involved in the manufacture of compound NPK fertilizers?

To better discuss the question presented above, we first briefly describe the main technical operations and steps involved in a modern factory of compound NPK fertilizers.

\section{Manufacture of compound NPK fertilizers and its effects on the stability of humic-derived compounds}

In Fig. 5, we describe the main operational steps included in a standard factory to manufacture compound NPK fertilizers [44].
This type of factory involves many steps, but we focus our interest on four main steps that might affect the efficiency of compound NPK fertilizers containing humic acids when incorporated during the granulation process [44]:

Step I Pre-granulation reactions (PGR).

This technical operation consists of pre-mixing specific raw materials to produce a liquid-slurry phase mass that is further added to the granulator drum in order to favor the granulation process. This step may include several complementary reactors [44]. 


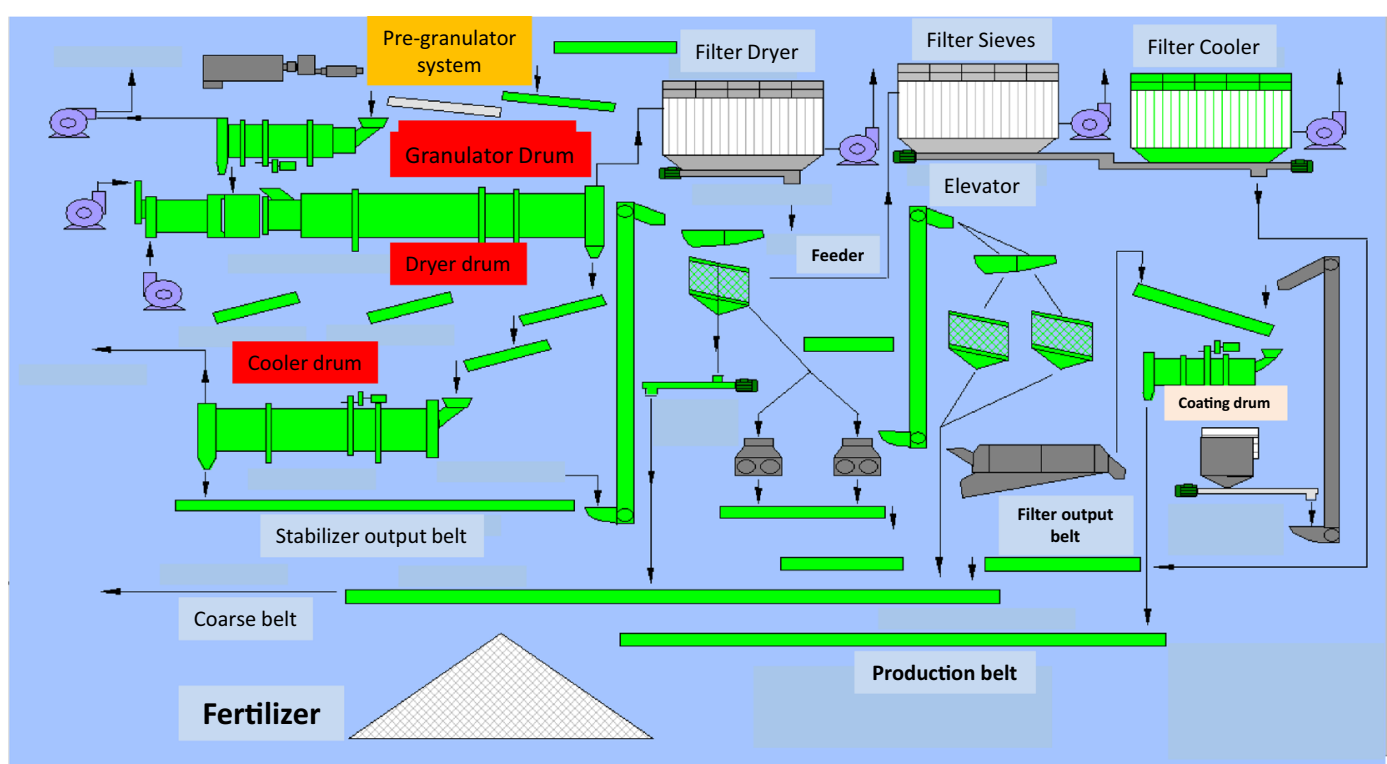

Fig. 5 Diagram of the main operations units involved in the manufacture of compound NPK granulated fertilizers (with José Miguel Urbieta and Marcos Boya permission)

A typical reactor is a pre-neutralizer reactor-normally a pipe reactor type (Fig. 6) - where liquid or gas ammonia is mixed with a mineral acid mainly sulfuric and/or phosphoric or nitric acid and projected to the granulator drum, which contains solid raw materials. This method is called chemical granulation. In this case, the granule is mainly formed by accretion (layer-type granule growth).

Another type of reactor is a pre-mixer-normally a lodige mixer type (Fig. 6) - where some raw materials (for instance, urea, diammonium phosphate, or potassium chloride) are mixed to each other with the simultaneous incorporation of water and/or heated steam, and further injected to the granulation drum. This method is called water/steam granulation. In this case, the granule is mainly formed by agglomeration through salt bridges [44].

When urea is included in the formula, a fraction may be melted in a specific reactor with steam and further added to the granulator drum [44].

All these processes involve high temperatures (around $100-120^{\circ} \mathrm{C}$ or more depending on the solution saturation
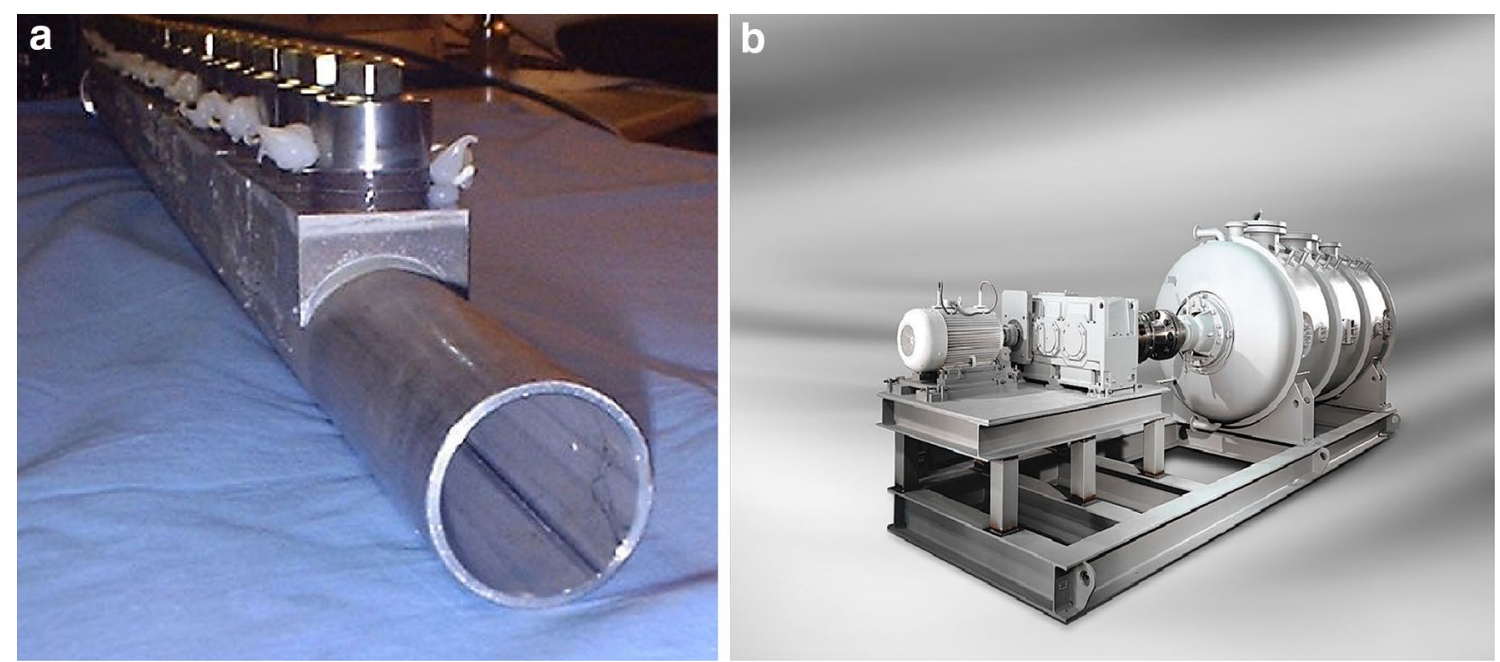

Fig. 6 a Pipe reactor design; b Lodige design 
degree) and normally acidic $\mathrm{pH}$ [44]. All these conditions favor ion exchange and new compounds formation during PGR. Therefore, this step can be used to synthesize new compounds from specific raw materials to be further included in the fertilizer granule during the granulation process, and it can also negatively affect the stability and structure of specific compounds that are intended to be introduced in the granule such as metal-humic complexes. When these negative effects lead to a decrease in the water solubility of mineral nutrients, this process is called retrogradation [44].

An important pre-granulation process is also the manufacture of superphosphates, either simple superphosphate (SSP) or triple superphosphate (TSP) (Fig. 7). SSP, which was developed in 1840, and TSP, that was developed later based on SSP process, result from the attack of ground phosphate rock with sulfuric acid and/ or phosphoric acid [44]. This process favors the formation of mostly water-soluble monocalcium phosphate, and low concentrations of dicalcium phosphate that is not only water soluble but is also soluble in neutral ammonium citrate (a reactant that extracts a $\mathrm{P}$ fraction considered as potentially available for plants) [44]. In superphosphates, involving sulfuric acid attack, high concentrations of partially hydrated calcium sulfate are also formed [44].
Step II Granulation process (GP).

This step consists of mixing the slurry phase coming from step I with ground solid raw materials, normally superphosphate and potassium salts (chloride or sulfate), in a rotary drum type (Fig. 8), to produce granules with specific size distribution [44]. This step may also be complemented by the addition of solid or liquid binders to improve agglomeration and granule formation, such as vinasses, lignosulfonates, celluloses, anhydrites, or clays [44]. Temperature and $\mathrm{pH}$ conditions are milder than in step I but still enough to favor the hydrolysis of compounds like metal chelates, metal-humic complexes or other types of organic molecules.

\section{Step III Drying-cooling process (DCP).}

This step involves two connected rotary drums (Fig. 4) [44]. The first one, the dryer, is used to dry fertilizer granules by flowing crosscurrent heated air (between 300 and $800{ }^{\circ} \mathrm{C}$ at the drum entry, depending on the raw materials used to obtain the granule) to granules running inside the drum [44]. Temperatures at granule surface reach around $90{ }^{\circ} \mathrm{C}$ and granule humidity is reduced from $8-10 \%$ to less than $1 \%$ [44]. It becomes clear that this operation can not only favor the formation of new compounds, but

\section{Super-Phosphate simplified production method}
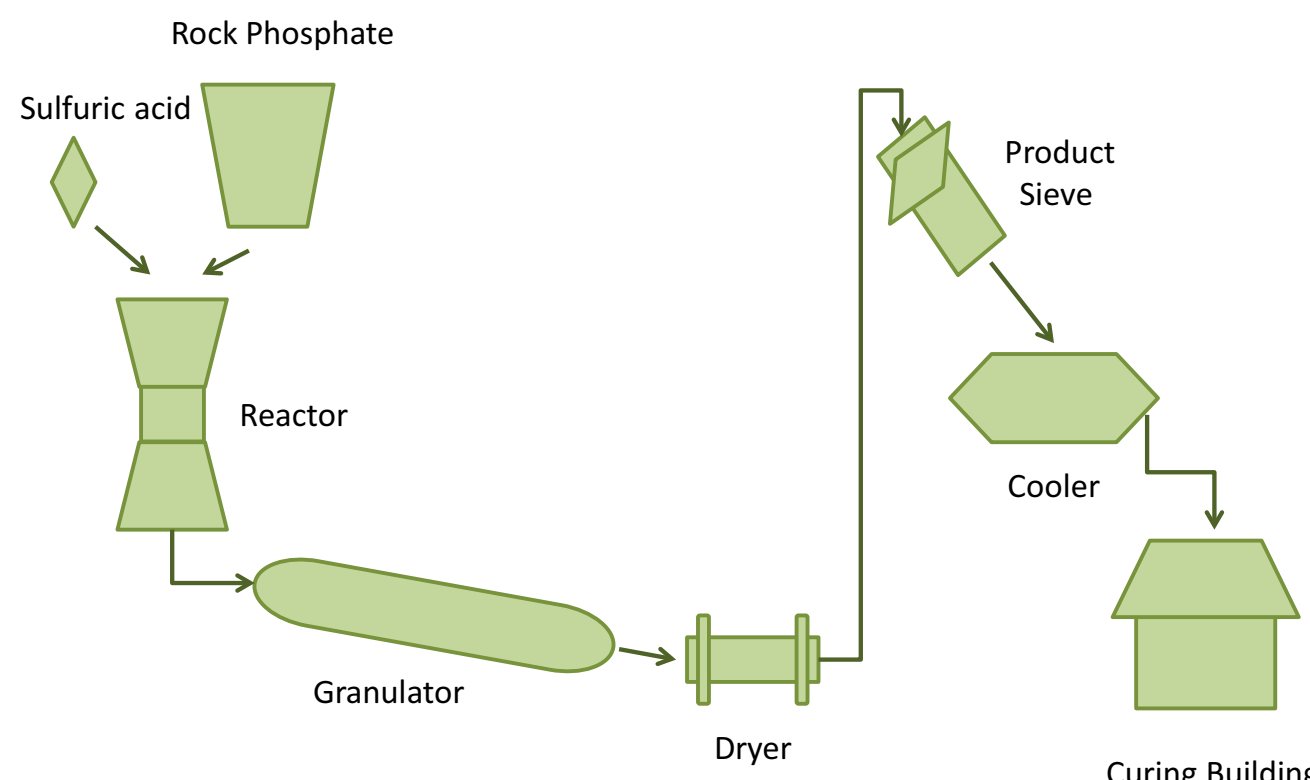

Curing Building

*with José Miguel Urbieta and Marcos Boya permission

Fig. 7 Diagram of the main operations units involved in superphosphate manufacture and further granulation 

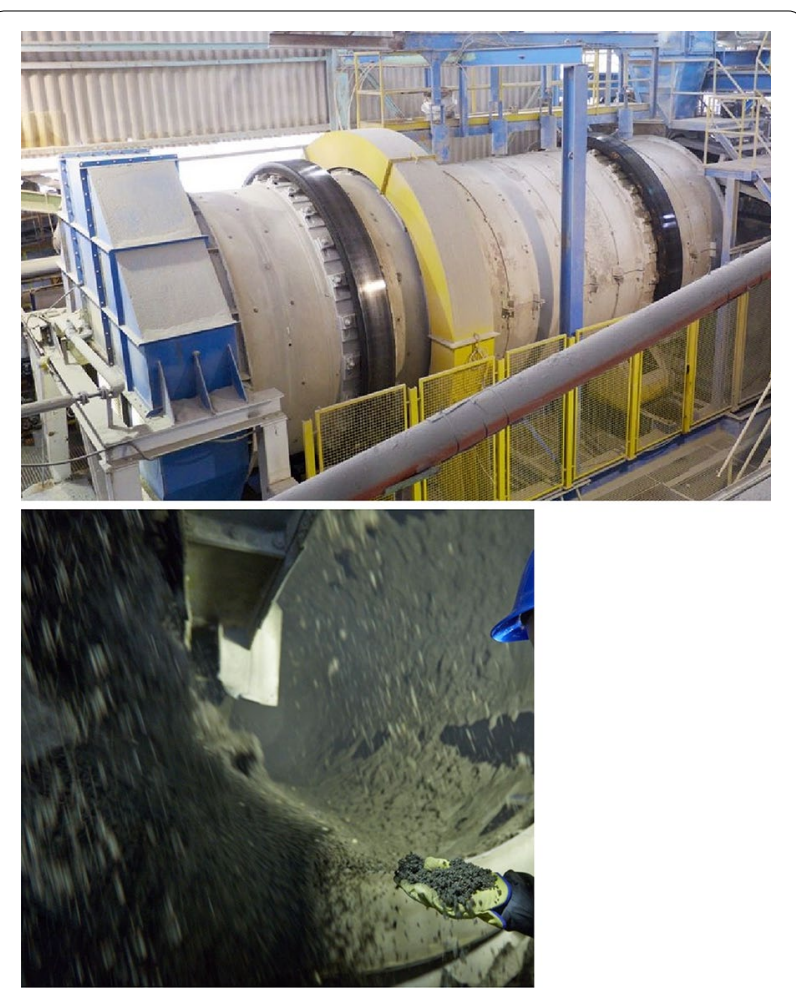

Fig. 8 Picture of a granulation drum and the running material inside it for granule formation (with permission of $\mathrm{M}$ Boya)

also the hydrolysis and/or decomposition of inorganic or organic nutritional molecules.

The second one, the cooler, is used to reduce granule temperature and stabilize the granule by stopping chemical reactions inside it, flowing crosscurrent air at room temperature to granules running inside the drum (Figs. 4, 5) [44]. Granule temperature is reduced from $60-80{ }^{\circ} \mathrm{C}$ to around $30^{\circ} \mathrm{C}$. Cooling can also be carried out using fluidbed coolers [44].

Step IV Conditioning process (CP).

This step consists of a rotary drum where the granule is coated with anti-caking agents like clays, talc, and oils, which may contain hydrophobic compounds (Fig. 4) [44].

This operation has great interest for us since it can be used to apply nutritional or biostimulant bioactive molecules thus avoiding the potential decomposition that may happen when they are applied during the granulation process. However, as will be further discussed below, the incorporation of active molecules as a coating has several constraints and only can be made when the proportion of these compounds in fertilizer formula is low (normally below $1 \%)$.

In summary we can conclude that:
Steps (operations) I-III (PGR, GP, DCP) may be useful tools to create new compounds with potential beneficial effects on plant nutrition and development, but they may cause added bioactive molecules to decompose thus losing their beneficial effects on plant nutrition and development.

The Step (operation) IV (CP) may be a useful tool to incorporate bioactive molecules into the granule surface thus avoiding the potential problems concerning molecular stability associated with steps I-III.

\section{Strategies to efficiently incorporate humic-derived compounds to compound NPK granular fertilizers}

In this chapter, we consider the incorporation into NPK compound fertilizers of two types of humic-based products with the ability to improve nutrient availability for soil cultivated plants:

(i) The incorporation of previously synthesized metalhumic complexes or phosphate-metal-humic complexes, with beneficial effects on mineral plant nutrition.

(ii) The fabrication of metal-humic complexes or phosphate-metal-humic complexes during the manufacture of compound NPK fertilizers, with beneficial effects on plant mineral nutrition.

\section{Incorporation to NPK compound fertilizers of previously synthesized humic mineral complexes}

The incorporation of humic complexes with nutritional action in plants, into the NPK granule, can be made through their incorporation either into one of the operational steps involved in the granule formation (I-III) or after granule stabilization in the conditioner drum. Although the latter option seems to be more adequate to prevent any decomposition of the molecules, many times it is not possible because it is very expensive due to the technology involved in it, and in many cases, the amount of humic mineral complexes needed to achieve intended results is too high to be applied by coating. In this sense, more than $1 \%$ in the formula is normally not suitable to be applied as a coating. Then, regarding to the humicderived molecules considered in this study, those related to micronutrients might be applied by coating (micronutrient concentration in compound fertilizer is rather low, mainly around $0.1 \%$ referred to the micronutrient), while those involving major nutrients in fertilizer formula, such as macronutrients and even secondary nutrients (for instance, $\mathrm{Ca}$ and $\mathrm{Mg}$ ), have to be applied in the granule mass during the granulation process.

Current practice involves the incorporation of mineral humic complexes, like micronutrient-humic complexes, into the NPK granule during the main granulation process 
(steps I-III) [9, 10, 38, 44]. However, this option-though less expensive-is not very efficient due to the losses in the efficacy of micronutrient-humic complexes resulting from decomposition or structural modifications caused by granulation conditions (mainly, temperature and $\mathrm{pH}$ ).

As an example, we describe here the effects of steps I-III on the stability and main agronomical properties of Fe chelates and Fe-humic complexes. It is very well known that alkaline and calcareous soils favor Fe unavailability for plants and microorganisms [45]. To prevent this problem, farmers use Fe chelates or complexes potentially able to keep $\mathrm{Fe}$ in soil solution by avoiding Fe precipitation [45]. In some arable crops like cereals that are not irrigated by either drip or sprinkler irrigation, the root application of Fe chelates in aqueous solutions is rather complicated and thereby their application along with NPK fertilizer granules has great interest.

To assess the effects of granulation on the potential efficiency of $\mathrm{Fe}$ compounds when they are incorporated into the granule during the main granulation process, we investigated Fe water solubility before and after granulation (unpublished results). The Fe products used in this research are described in Table 1 . We used synthetic Fe chelates, Fe humic complexes, Fe sulfate and Fe oxide as a control. All Fe products were incorporated in step II (GP) (unpublished results).

Results clearly show that the granulation process caused a total loss of Fe water solubility in NPK granules produced with Fe sulfate and Fe humic complexes (Table 2) (unpublished results). This fact indicated that granulation favored the formation of new Fe compounds with low water solubility. The fact that the water-soluble fraction of $\mathrm{P}$ also decreased after granulation in these NPK fertilizers indicated that those new Fe compounds

Table 1 Total and water-soluble (W) Fe \% and $P\left(P_{2} \mathbf{O}_{5}\right) \%$, in the Fe- and P-sources used in the manufacture of NPK compound fertilizer

\begin{tabular}{lllll}
\hline Products & Total Fe $\%$ & W-Fe $\%$ & Total P $\%^{\mathbf{a}}$ & W-P $\%^{\mathbf{a}}$ \\
\hline Fe products & & & & \\
FeHEDTA & 13.0 & 13.0 & - & - \\
FeDTPA & 11.9 & 11.9 & - & - \\
FeEDTA & 14.1 & 14.1 & - & - \\
$\mathrm{FeSO}_{4}$ & 20.1 & 20.1 & - & - \\
$\mathrm{Fe}_{2} \mathrm{O}_{3}$ & 69.9 & 0 & - & - \\
P products & & & & \\
DAP & 0.182 & 0.022 & 46.5 & 43.8 \\
TSP & 0.175 & 0.025 & 46.4 & 39.1 \\
\hline
\end{tabular}

Fe in DAP and TSP results from its presence in the raw materials used to DAP and TSP manufacture process (mainly, in phosphoric acid and rock phosphate)

a $P$ is expressed as $\mathrm{P}_{2} \mathrm{O}_{5}$
Table 2 Total and water-soluble contents of $\mathrm{Fe}(\%)$ and $\mathrm{P}_{2} \mathrm{O}_{5}(\%)$ in compound fertilizers after the manufacturing process ( $\mathrm{Fe} \%: \mathrm{P}_{2} \mathrm{O}_{5} \%$ ratio of $0.1: 10$ in NPK formula)

\begin{tabular}{|c|c|c|c|c|}
\hline \multirow[t]{2}{*}{ Fertilizers } & \multicolumn{2}{|c|}{$\mathrm{Fe}(\%)$} & \multicolumn{2}{|c|}{$\mathrm{P}_{2} \mathrm{O}_{5}(\%)$} \\
\hline & Total & Water & Total & Water \\
\hline \multicolumn{5}{|l|}{ । } \\
\hline $\mathrm{FeSO}_{4}: \mathrm{TSP}$ & 0.82 & 0.032 & 47.5 & 40.8 \\
\hline $\mathrm{FeSO}_{4}: \mathrm{DAP}$ & 0.85 & 0.022 & 46.5 & 43.0 \\
\hline Fe2O3:TSP & 0.34 & 0 & 47.1 & 41.3 \\
\hline $\mathrm{Fe}_{2} \mathrm{O}_{3}: \mathrm{DAP}$ & 0.38 & 0 & 45.5 & 44.0 \\
\hline \multicolumn{5}{|l|}{$\|$} \\
\hline FeEDTA:TSP & 0.70 & 0.50 & 46.5 & 40.2 \\
\hline FeEDTA:DAP & 0.84 & 0.48 & 45.5 & 43.2 \\
\hline FeDTPA:TSP & 0.77 & 0.49 & 45.0 & 39.4 \\
\hline FeDTPA:DAP & 0.69 & 0.45 & 44.4 & 41.2 \\
\hline FeHEDTA:TSP & 0.70 & 0.41 & 46.3 & 38.8 \\
\hline FeHEDTA:DAP & 0.70 & 0.42 & 44.7 & 42.2 \\
\hline Fe-HA:TSP & 0.80 & 0 & 45.0 & 40.0 \\
\hline $\mathrm{Fe}-\mathrm{HA}: \mathrm{DAP}$ & 0.91 & 0 & 44.6 & 39.8 \\
\hline
\end{tabular}

$T S P$ (triple superphosphate) and DAP (diammonium phosphate) are $\mathrm{P}$ sources in NPK fertilizers

I inorganic Fe sources; // Fe chelates and Fe-humic complexes

are probably related to Fe phosphates (Table 2) (unpublished results).

In the case of synthetic Fe chelates, which have higher stability than Fe-humic complexes, the loss of Fe water solubility was lower than in the case of Fe-humic complexes, but still very significant (Table 2) (unpublished results). Also in this case it was observed a decrease in $\mathrm{P}$ water solubility, indicating that both $\mathrm{Fe}$ and $\mathrm{P}$ retrogradation were related to the formation of Fe phosphates during granulation (Table 2) (unpublished results).

These results illustrate the negative consequences of the whole granulation process (steps I-III) on the stability and chemical features of these types of compounds, which are currently used to prevent micronutrient deficiencies in plants.

Conversely, when these types of compounds were applied in the conditioner drum as a coating, their main physicochemical properties and structures were preserved [38]. However, in this case it is necessary to find the binder agent able to maintain the product stable on granule surface over time, without negatively affecting granule conservation during storage. This problem is sometimes complicated to solve depending on fertilizer formulation, but, at least so far, coating is in our opinion the best technical option to assure the agronomic efficiency of these types of compounds incorporated into NPK compound fertilizer granules when applied to the field. 
To develop an adequate technology of coating for applying these types of products (for instance, micronutrient correctors and also other types of products like biostimulants) on granule surface it would be necessary to consider, among others, the following issues [44]:

\section{- Granule hygroscopicity.}

This parameter has great importance to select liquid binders, since it directly affects granule conservation features (mainly caking) during storage [44].

- Roughness and texture of granule surface.

- Chemical stability and solubility features of humicbased complexes.

- Particle size distribution of humic-based complexes when applied in solid form: The lower the size particle the better the coating quality.

Although there are several possible strategies to develop an adequate coating, our experience indicates that the application of humic-mineral complexes in powder form dispersed in a liquid binder, such as vegetal oil or a resin, along with a drying powder like kaolin, or talk, normally gives satisfactory results.

However, as stated above, the use of NPK granule coating to apply additives has some limitations, mainly related to the maximum amount of additives that can be applied properly, binder compatibility with both granule composition and additives, the chemical stability of additives and the potential biodegradability of binders and/or additives on granule surface.

\section{The fabrication of humic-mineral complexes during the manufacture process of compound NPK fertilizers}

As stated above, when humic-mineral complexes concern macronutrients or secondary nutrients, these compounds cannot be applied as a coating due to their high proportion in the granule formula. In these cases, the only possibility is to obtain these new compounds during some of the steps involved in the granulation process taking advantage of the energy (heat), concentration in solution and $\mathrm{pH}$ conditions involved in them.

Regarding $\mathrm{N}$ and $\mathrm{K}$, previous studies indicated that the beneficial action of HS on these two macronutrients, when applied in NPK compound fertilizer, is rather low and probably derive from improvements of the plant uptake of other nutrients with scarce potential bioavailability in some types of soils, such us Fe and $\mathrm{Zn}$ in calcareous soils and $\mathrm{P}$ in both calcareous and acidic soils $[4,10,13]$. This may result from the fact that the various N-forms used in NPK compound fertilizers such as ammonium and urea, and $\mathrm{K}^{+}$as well, form weak bonds (hydrogen bonds for urea, and ionic bonds for $\mathrm{NH}_{4}^{+}$ and $\mathrm{K}^{+}$) with the anionic binding sites in HS [3]. However, when $\mathrm{N}$ (ammonium, urea or nitrate) or $\mathrm{K}$ salts are incorporated in liquid formulations containing $\mathrm{HS}$ and applied in drip irrigation (fertigation), improvements in $\mathrm{N}$ and $\mathrm{K}$ plant fertilization are more consistent and probably result from the direct action of HS on the transport of these nutrients into plant root [5-7].

As for $\mathrm{P}$, as mentioned before some studies suggested that the formation in soil solution of stable humic-metal (mainly $\mathrm{Fe}, \mathrm{Al}$ )-phosphate complexes was involved in the improvement of P-bioavailability associated to humic matter in soils and soil solution [39]. Further studies demonstrated that these types of humic-metalphosphate complexes can be obtained in the laboratory [40-43]. These studies also showed that these complexes were stable and soluble in soil solutions with $\mathrm{pH}$ values ranked between 4 and 8 [41, 42]. Other studies showed that these humic-metal-phosphate complexes prevented phosphate soil fixation and provided available P to different plant species [46]. Therefore, the application of these types of humic-metal-phosphate complexes has great potential interest to enhance the agronomic efficiency of P-compound fertilizers. However, as stated above, the high concentration of $\mathrm{P}$ in compound fertilizers makes impossible to apply it as humic-metal-phosphate complexes during fertilizer conditioning and coating (step IV in fertilizer manufacture process). Therefore, the only way to take advantage of these types of P-metal-humic complexes would be their production during some step involved in the granulation process (steps I-III in fertilizer manufacture process), mainly step I.

A number of studies have shown that the simultaneous reaction of phosphoric acid with alkaline compounds containing $\mathrm{Mg}$ (MgO products), and metals (for instance, $\mathrm{Zn}$ or Fe oxides or carbonates) in the presence of specific amounts of potassium or sodium salts of humic acids produced humic-double metal-phosphate complexes [47]. These complexes were identified in solid matrices using ${ }^{31} \mathrm{P}-\mathrm{NMR}$ as described in Riggle and von Wandruska [42] and Erro et al. [48]. The final product is a solid powder, with a texture similar to that of SSP, which may be employed for compound fertilizer granulation as a raw material.

This reaction can be carried out in a factory similar to that for SSP manufacture [44]. Obtained humic-metalphosphate complexes were only partially soluble in water but totally soluble in rhizospheric root exudates and neutral ammonium citrate (an indicator of potential P availability for plants) $[47,49]$. The main interest of compound fertilizers based on these types of complexes is that their potential soil fixation (P retrogradation) and leaching are very low due to their low water solubility, while they are 
able to provide available $\mathrm{P}$ for plants $[46,47]$. However, plant roots need to interact in some way with fertilizer granule to solubilize phosphate by the action of root exudates [46, 47] (Fig. 9). Consequently, these fertilizers, called Rizosphere Controlled Fertilizers (RCF) [47], are sensitive to plant $P$ needs in some way since their efficiency implies the activation of some of the root-specific responses to $\mathrm{P}$ limitation [46, 47].

A very interesting finding associated with RCF usage in field crops is that the P use efficiency (defined as the produced shoot-yield:leaf-P concentration ratio) in leaves increased very significantly compared to the normal compound fertilizers $[46,47]$. This fact suggested that RCF were able to trigger the regulation pathways involved in shoot P needs-root P uptake crosstalk (Fig. 10) [50]. As $P$ uptake from RCF implies additional energy, plants tend to optimize $\mathrm{P}$ usage in shoots and minimize P uptake in roots [50].

In another set of studies, the production of specialtype SSP containing monocalcium phosphate complexed by humic-binding sites through $\mathrm{Ca}$ bridges was also explored [51]. The main chemical process used for the manufacture of this special fertilizer was implemented into the main manufacture process employed for SSP production [51]. Tested reactions involved both SSP (rock phosphate-sulfuric acid reaction) and TSP (rock phosphate-phosphoric acid reaction) [51]. The reaction included the attack of rock phosphate with the mineral acid (sulfuric and/or phosphoric) in the presence of specific amounts of sodium or potassium salts of humic acid [51]. Under SSP manufacture reaction conditions,

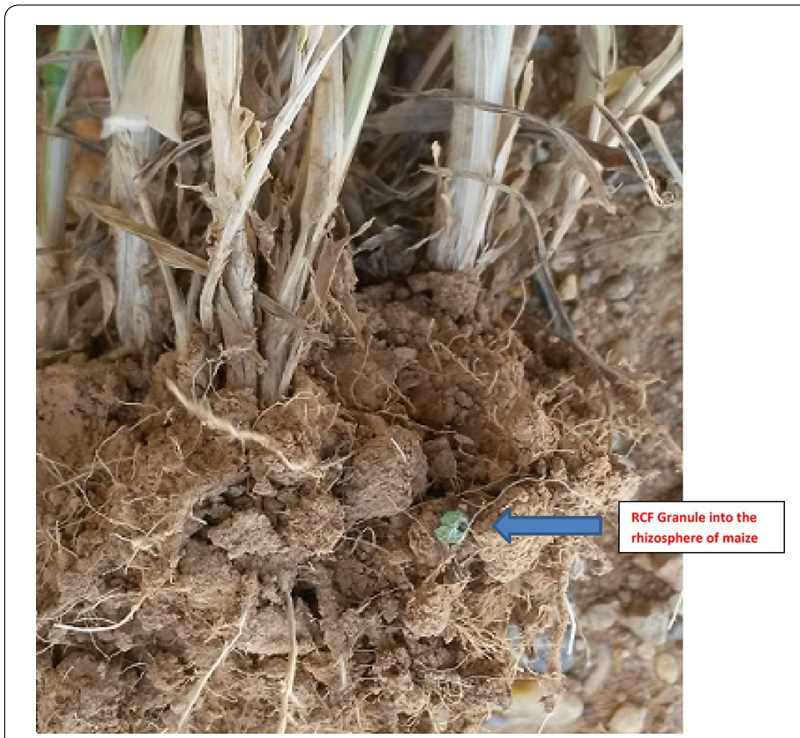

Fig. 9 Interaction of RCF fertilizer granule with maize roots (with permission of Mr. Malanda) the formation of stable humic-monocalcium phosphate complexes was proved using both ${ }^{31} \mathrm{P}-\mathrm{NMR}$ and theoretical computational calculations and this type of new SSP was called CSP (complexed superphosphate) [51, 52] (Fig. 11). Several studies showed its efficiency to prevent $P$ from retrogradation in $P$ fixing soils $[51,53]$. This fact was consistent with the $\mathrm{P}$ remaining as plant available in soils with high P fixing ability-either calcareous or acidic with high clay and $\mathrm{Fe}-\mathrm{Al}$ contents-after incubation with CSP over time $[51,53]$.

The physical appearance and texture of CSP is very similar to that of ordinary SSPs and it can be employed as a raw material to produce both CSP granular fertilizers and compound NPK fertilizers containing CSP as P-source.

The main difference between RCF and CSP is that the former involves metal double-binding bridges between humic and phosphate, while the latter involves calciumbinding bridges $[46,47,51,52]$. $\mathrm{P}$ in RCF is poorly soluble but sensitive to the root exudation associated with root responses to P-limiting conditions, while in CSP is water soluble and the role of root exudates is probably different in some way (improvements in P shoot use efficiency were also observed for CSP) [50].

Although the structure of humic-metal-phosphate complexes in the fertilizer matrix is not known, it seems clear that the P:humic ratio in reaction components is too high for a total stoichiometric P complexation taking place. However, results showed that a decrease in P:humic ratio below a specific value did not lead to better $\mathrm{P}$ complexation when evaluated by both ${ }^{31} \mathrm{P}-\mathrm{NMR}$ and agronomical results [47, 51]. These findings might be explained as a result of some type of interaction-field induced in SSP crystal matrix by the inclusion of humic molecules in calcium or metal phosphate lattices [52]. These studies also showed that calcium sulfate is probably complexed by humic molecules through calciumbinding bridges in CSP [52].

Overall, these studies highlight the great agronomical interest of compound NPK fertilizers including humic-mineral complexes. These complexes can be applied either as a coating on granule surface (micronutrient-humic products) or into the mass of the granule during the granulation process (macronutrient-humic products).

Less efficient, but still beneficial, humic-NPK compound fertilizers can be obtained when applying humate solutions during the granulation process on the massnormally-into the granulation drum $[9,38]$. In this case, reaction conditions are milder than those involved in RCF or CSP manufacture, and chemical bonds between HS and nutrients are weaker that those involved in RCF and CSP matrices [38]. Humic-NPK compound 


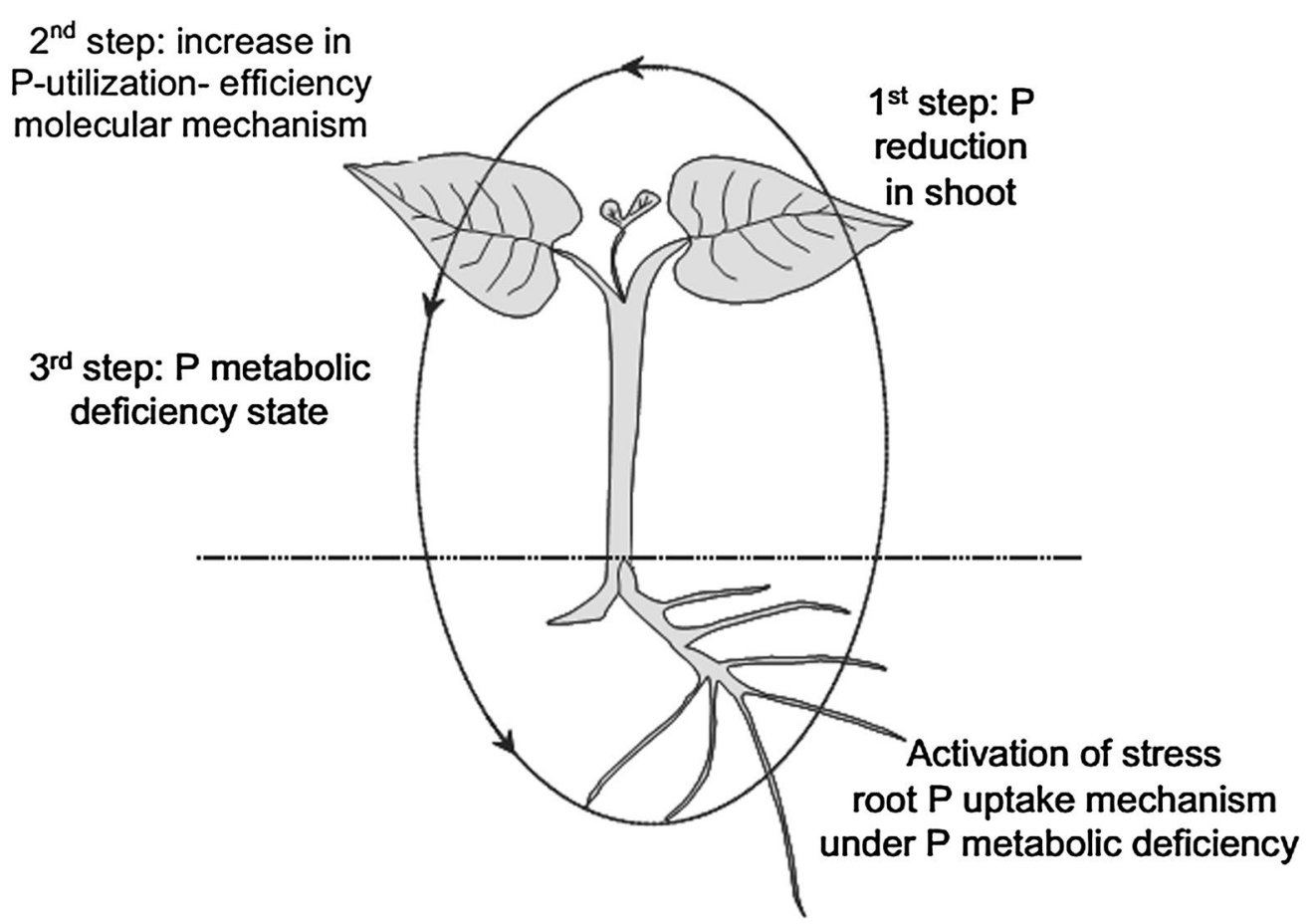

Fig. 10 Coordinated model for the regulation of nutrient-stress root responses (from [50])

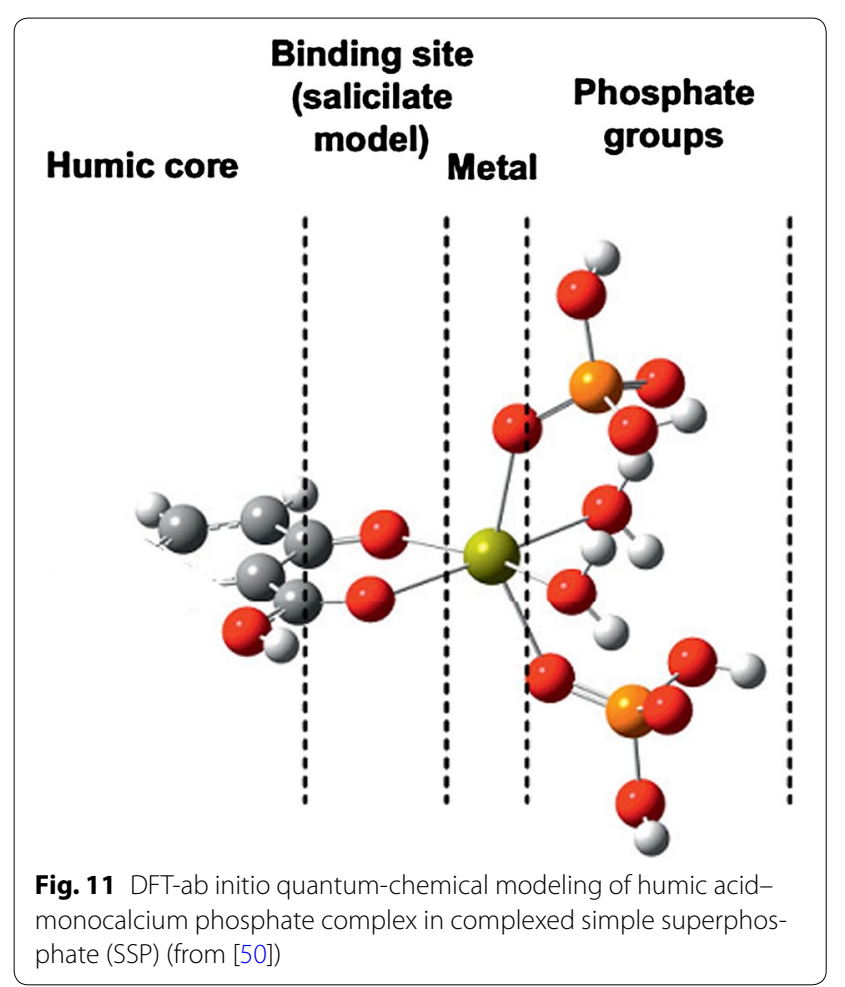

fertilizers produced in this way have shown higher efficiency than ordinary NPK compound fertilizers [9, 38]. These effects were mainly related to the ability of HA to improve nutrient fertilizer availability since normally the active HA dose per ha applied with NPK granules is too low for developing HA-DE mediated effects on plant crops. Indeed, Chen and Aviad [4] calculated that around $75 \mathrm{~kg}$ per ha of $\mathrm{HA}$ is needed to have consistent biostimulant effects on field crops. This means that the manufacture of a compound NPK fertilizer contains at least $20 \%$ of potentially active HA in the formula, when the NPK fertilizer dose used is $400 \mathrm{~kg}$ per ha. Although very expensive, this fertilizer can be prepared by adding HA as a raw material for granulation. However, the above-explained extreme conditions of temperature, and principally, $\mathrm{pH}$ within the granulation drum as well as the presence of polyvalent cations in the solution of granulation $\left(\mathrm{Ca}^{++}\right.$for instance), normally lead to HA precipitation and insolubility. This fact, in turn, implies a significant potential loss in agronomical efficiency.

\section{Final remarks}

Overall, a number of basic and applied studies have shown the suitability of including humic mineral 
complexes with beneficial effects on plant nutrition and development into the granules of NPK compound fertilizers. These studies suggested that:

1. When the amount of humic-mineral complexes to achieve the intended agronomical results is low compared with the total NPK formula (normally below $1 \%$ ), they should be incorporated to granule surface as a coating to minimize their decomposition and assure their optimal agronomical activity. This is the case of humic-micronutrient complexes. This reasoning would also be valid for the incorporation on NPK granules of bioactive molecules with stimulant or plant regulatory properties.

2. When the intended humic beneficial effect refer to macronutrients $(\mathrm{N}, \mathrm{P}$ or $\mathrm{K})$ and secondary nutrients ( $\mathrm{Mg}$ or $\mathrm{Ca}$ ), which are in high proportion in fertilizer formula, the most efficient method for their incorporation into NPK granule is the fabrication of humic mineral complexes ( $\mathrm{P}, \mathrm{Ca}$ and $\mathrm{Mg}$ ) or humates ( $\mathrm{K}$ and ammonium) during the granulation process.

3. The preparation of simpler humic-NPK compound fertilizers with improved agronomical efficiency can be afforded by the incorporation of humates during the granulation process.

4. On the contrary, in our opinion, when the interest is focused on the DE of HS, it is normally much more efficient the formulation of liquid products (solid water-soluble products) with high concentration of HS (in aqueous alkaline solution, usually, the maximum amount of humic substances that is stable in solutions is around $20 \%$ ), which are applied by foliar or drip irrigation (fertigation).

\section{Authors' contributions}

JE, OU, RB, MF and AMZ contributed to MS preparation; JMGM contributed to MS preparation and final writing. All authors read and approved the final manuscript.

\section{Author details \\ ${ }^{1}$ Department of Environmental Biology, Agricultural Chemistry and Biology Group/CMI Roullier, Faculties of Sciences and Pharmacy, University of Navarra, c/Irunlarrea 1, 31080 Pamplona, Navarra, Spain. ${ }^{2}$ Department of Technical Development, Timac Agro Spain, Factory, C/Feculas, Lodosa, Spain.}

\section{Acknowledgements}

This Research Project has been supported by Grants from CDTI and Government of Navarra, as well as the Roullier Group.

\section{Competing interests}

The authors declare that they have no competing interests.

Received: 7 December 2015 Accepted: 6 May 2016

Published online: 04 June 2016

\section{References}

1. MacCarthy P, Clapp CE, Malcom RE, Bloom PR. Humic substances in soil and crop sciences: selected readings. Madison: American Society of Agronomy and Soil Science Society of America; 1990.

2. Magdoff F, Weil R. Soil organic matter in sustainable agriculture. Boca Raton: CRC Press LLC; 2004.

3. Stevenson FJ. Humus chemistry: genesis, composition, reactions. Hoboken: Wiley; 1994.

4. Chen Y, Aviad T. Effects of humic substances on plant growth. In: MacCarthy P, Malcom RE, Clapp CE, Bloom PR, editors. Humic substances in soil and crop science: selected readings. Madison: Americal Society of Agronomy and Soil Science Society of America; 1990. p. 161-87.

5. Mora V, Olaetxea M, Bacaicoa E, Baigorri R, Fuentes M, Zamarrerreño AM, Garcia-Mina JM. Abiotic stress tolerance in plants: exploring the role of nitric oxide and humic substances. In: Khan NM, Mobin M, Firoz M, Corpas FJ, editors. Nitric oxide in plants: metabolism and role in stress physiology. Berlin: Springer; 2014. p. 243-64.

6. Rose MT, Patti AF, Little KR, Brown AL, Jackson WR, Cavagnaro TR. A meta-analysis and review of plant-growth response to humic substances: practical implications for agriculture. Adv Agron. 2014;124:37-89.

7. Canellas LP, Olivares FL, Aguiar NO, Jones DL, Nebbioso A, Mazzei P, Piccolo A. Humic and fulvic acids as biostimulants in horticulture. Sci Hortic. 2015;196:15-27.

8. de Liñan C. Vademecum de productos fitosanitarios y nutricionales. Madrid: Ediciones Agrotecnicas; 2014.

9. Benedetti A, Figliola A, Izza C, Indiati R, Canali S. Fertilization with NPK and humate NPK: plant yield and nutrient dynamics. Suelo y Planta. 1992;2:203-14.

10. Garcia-Mina JM. Fertilizantes complejos órgano-minerales. In: Juarez M, Sanchez-Andreu J, editors. Fosforo en agricultura. Alicante: Universidad de Alicante; 1992. p. 129-35.

11. Senesi N. Metal-humic substance complexes in the environment. Molecular and mechanistic aspects by multiple spectroscopic approach. In: Adriano CM, editor. Biogeochemistry of trace metals. New York: Lewis Publishers; 1992. p. 429-96.

12. Tipping E. Cation binding by humic substances. Cambridge: Cambridge University Press; 2002.

13. Chen Y, De Nobili M, Aviad T. Stimulatory effects of humic substances on plant growth. In: Magdoff F, Weil R, editors. Soil organic matter in sustainable agriculture. Boca Raton: CRC Press; 2004. p. 103-29.

14. Tan KH. Humic matter in soil and the environment. Principles and controversies. New York: Marcel Dekker Inc; 2003.

15. Hodgson JF. Contribution of metal-organic complexing agents to the transport of metals to roots. Soil Sci Soc Am Proc. 1969;33:68-75.

16. Hodgson JF, Geering HR, Norwell WA. Micronutrient cation complexes in soil solution: I. Partition between complexed and uncomplexed forms by solvent extraction. Soil Sci Soci Am J. 1965;29:665-9.

17. Geering HR, Hodgson JF, Sdano C. Micronutrient cation complexes in soil solution: IV. The chemical state of manganese in soil solution. Soil Sci Soci Am J. 1969:33:81-5.

18. Piccolo A. The supramolecular structure of humic substances: a novel understanding of humus chemistry and implications in soil science. Adv Agron. 2002;75:57-134

19. García-Mina JM. Advantages and limitations of the use of an extended polyelectrolyte model to describe the proton-binding process in macromolecular systems. Application to a poly(acrylic acid) and a humic acid. J Phys Chem B. 2007;111:4488-94.

20. García-Mina JM, Antolín MC, Sanchez-Diaz M. Metal-humic complexes and plant micronutrient uptake: a study based on different plant species cultivated in diverse soil types. Plant Soil. 2004;258:57-68.

21. Garcia-Mina JM. Stability, solubility and maximum metal binding capacity in metal-humic complexes involving humic substances extracted from peat and organic compost. Org Geochem. 2006;37:1960-72.

22. Loué A. Oligoelements en agriculture. Paris: Editions Natham; 1993.

23. Ennis MT, Brogan JC. The availability of copper from copper-humic acid complexes. Irish J Agric Res. 1961;1:35-42. 
24. Ennis MT. Some copper-complexing properties of peat. Irish J Agric Res. 1962;1:139-47.

25. Gupta SK, Häni H. Effect of copper supplied in the form of different Cusaturated sludge samples and copper salts on the $\mathrm{Cu}$-concentration and dry matter yield of corn grown in sand. In: L'Hermite P, Dehand-Schutter J, editors. Symposium on copper in animal wastes and sewage sludge. Dordrecht: Reidel Publishing Co; 1980. p. 67-9.

26. Gupta SK. Bioverfuegbarkeit von Kupfer in einem Huminsaeure-und Klaerschlamm-komplex. Mitteilgn Dtsch Bodenkundl Gesellsch. 1986:45:61-6.

27. Barnard RO, Watt H, Dekker J, Cronje I, Mentz WH, Cillie GEB, Laker MC Application of Fe and $\mathrm{Zn}$ to lime-rich soils in the form of formulated coal products. Sci Total Environ. 1992;117(118):569-74.

28. Miravé JP, Orioli GA. Zinc absorption and transport from complete humate and high and medium molecular weight fractions. Sci Total Environ. 1989;81(82):679-82.

29. Kumar M, Prasad B. The relative contribution of natural zinc complexing agents and $\mathrm{ZnSO}_{4}$ to growth and zinc nutrition of maize. J Nucl Agric Biol. 1989;18:29-35.

30. Barton JJ, Abadía J. Iron nutrition in plants and rhizospheric microorganisms. Berlin: Springer; 2006.

31. Miravé JP, Lobartini JC, Orioli GA. Absorción y transporte de hierro a partir de fuentes orgánicas de distinto peso molecular. Ci Suelo. 1987;5:31-5.

32. Lobartini JC, Orioli GA. Absorption of iron Fe-humate in nutrient solutions by plants. Plant Soil. 1988;106:153-7.

33. Pinton R, Cesco S, Santi S, Agnolon F, Varanini Z. Water-extractable humic substances enhance iron deficiency responses by Fe-deficient cucumber plants. Plant Soil. 1999;210:145-57.

34. Burau RG, White RG, MacGregor JM. Uptake of applied iron by soybeans from calcareous soil treated with peat-based humates and synthetic chelates. Trans 7th Intl Congr Soil Sci. 1960;3:544-53.

35. Alva AK, Obreza TA. By-product iron-humate increases tree growth and fruit production of orange and grapefruit. HortScience. 1998;33:71-4.

36. Legaz F, Serna MD, Ferrer P, Cebolla V, Primo-Millo E. Nutritional diagnosis in citrus plants. Valencia: Generalitat Valenciana; 1995.

37. Pandeya SB, Singh AK, Dhar P. Influence of fulvic acid on transport of iron in soils and uptake by paddy seedlings. Plant Soil. 1998;198:117-25.

38. Sanchez-Diaz M, Garcia-Mina JM. Effet de l'association chimique NPK MGcomplexe organique activé sur le development vegetal et l'assimilation de nutrients pour les plantes. Inab-Rapp. 1994;72:1-7.

39. Gerke J. Humic (organic matter)-Al(Fe)-phosphate complexes: an underestimated phosphate form in soils and source of plant-available phosphate. Soil Sci. 2010;175:417-25.

40. Guardado I, Urrutia O, García-Mina JM. Methodological approach to the study of the formation and physicochemical properties of phosphatemetal-humic complexes in solution. J Agric Food Chem. 2005;53:8673-8.
41. Guardado I, Urrutia O, García-Mina JM. Size distribution, complexing capacity and stability of phosphate-metal-humic complexes. J Agric Food Chem. 2007;55:408-13.

42. Riggle J, von Wandruszka R. Binding of inorganic phosphate to dissolved metal humates. Talanta. 2005;66:372-5.

43. Guardado I, Urrutia O, García-Mina JM. Some structural and electronic features of the interaction of phosphate with metalhumic complexes. J Agric Food Chem. 2008;56:1035-42.

44. Lee RG, Kpytowski JA. Fertilizer manual. United Nations Industrial Development Organization (UNIDO) and International Fertilizer Development Center (IFDC). Dordrecht: Kluwer Academic Publishers; 1998.

45. Lucena JJ. Synthetic iron chelates to correct iron deficiency in plants. In: Barton LL, Abadía J, editors. Iron nutrition in plants and rhizospheric microorganisms. Dordrecht: Springer; 2006. p. 103-28.

46. Urrutia O, Guardado I, Erro J, Mandado M, García-Mina JM. Theoretical chemical characterization of phosphate-metal-humic complexes and relationships with their effects on both phosphorus soil fixation and phosphorus availability for plants. J Sci Food Agric. 2013;93:293-303.

47. Erro J, Urrutia O, San Francisco S, García-Mina JM. Development and agronomical validation of new fertilizer compositions of high bioavailability and reduced potential nutrient losses. J Agric Food Chem. 2007:66:7831-9.

48. Erro J, Baigorri R, Yvin JC, Garcia-Mina JM. ${ }^{31}$ P NMR characterization and efficiency of new types of water-insoluble phosphate fertilizers to supply plant-available phosphorus in Diverse soil types. J Agric Food Chem. 2011;59:1900-8.

49. Erro J, Zamarreño AM, García-Mina JM. Ability of different water insoluble fertilizers to supply available phosphorus in hydroponics to plant species with diverse phosphorus acquisition efficiency: involvement of organic acid accumulation in plant tissues and root exudates. J Plant Nutr Soil Sci. 2010;173:772-7.

50. Urrutia O, Erro J, Guardado I, San Francisco S, Mandado M, Baigorri R, Yvin JC, Garcia-Mina JM. Physico-chemical characterization of humic-metalphosphate complexes and their potential application to the manufacture of new types of phosphate-based fertilizers. J Plant Nutr Soil Sci. 2014;177:128-36

51. Erro J, Urrutia O, Baigorri R, Aparicio-Tejo P, Irigoyen I, Storino F, Mandado M, Yvin JC, Garcia-Mína JM. Organic complexed superphosphates (CSP): physicochemical characterization and agronomical properties. J Agric Food Chem. 2012;60:2008-17.

52. Baigorri R, Urrutia O, Erro J, Mandado M, Perez-Juste I, Garcia-Mina JM. Structural characterization of anion calcium-humate complexes in phosphate-based fertilizers. ChemSusChem. 2013;6:1245-51.

53. Giovannini C, Garcia-Mina JM, Ciavatta C, Marzadori C. Effect of organiccomplexed superphosphates on microbial biomass and microbial activity of soil. Biol Fertil Soil. 2013:49:395-401.

\section{Submit your manuscript to a SpringerOpen ${ }^{\circ}$ journal and benefit from:}

- Convenient online submission

- Rigorous peer review

- Immediate publication on acceptance

- Open access: articles freely available online

- High visibility within the field

- Retaining the copyright to your article

Submit your next manuscript at $\boldsymbol{\nabla}$ springeropen.com 